\title{
Wave data assimilation using a hybrid approach in the Persian Gulf
}

\author{
M.H.Moeini ${ }^{1}$, A.Etemad-Shahidi ${ }^{2}$, V.Chegini ${ }^{3}$, and I. Rahmani ${ }^{4}$ \\ ${ }^{1}$ School of Civil Engineering, Iran University of Science and Technology, Tehran, \\ Iran.
}

Tel.: +9821 77240399, Fax: +9821 77454053, Email: mhmoeini@iust.ac.ir, Etemad@iust.ac.ir

${ }^{2}$ Griffith School of Engineering, , Gold coast Campus, Griffith University, Gold Coast, QLD4222, Australia

${ }^{3}$ Iranian National institute for Oceanography. Tehran, Iran.
Email: v_chegini@inio.ac.ir

${ }^{4}$ Transportation Research Institute. Tehran, Iran.

Email: iraj.rahmani@gmail.com

\begin{abstract}
The main goal of this study is to develop an efficient approach for the assimilation of the hindcasted wave parameters in the Persian Gulf. Hence, the third generation SWAN model was employed for wave modeling forced by the 6-hourly ECMWF wind data with a resolution of $0.5^{\circ}$. In-situ wave measurements at two stations were utilized to evaluate the assimilation approaches. It was found that since the model errors are not the same for wave height and period, adaptation of model parameter does not result in simultaneous and comprehensive improvement of them. Therefore, an approach based on the error prediction and updating of output variables was employed to modify wave height and period. In this approach, artificial neural networks (ANNs) were used to estimate the deviations between the simulated and measured wave parameters. The results showed that updating of output variables leads to significant improvement in a wide range of the predicted wave characteristics. It was revealed that the best inputs parameters for error prediction networks are the mean wind speed, mean wind direction, wind duration and the modeled wave parameters. In addition, combination of the ANN estimated error with numerically modeled wave parameters leads to further improvement in the predicted wave parameters in contrast to direct estimation of the parameters by ANN.
\end{abstract}

Keywords: Persian Gulf, Wave hindcasting, Neural Network, SWAN, error prediction, 


\section{Introduction}

Wind-waves are the most important environmental factor in the design of coastal and offshore structures, sediment transport, coastal erosion etc. Therefore, an accurate assessment of the wave climate is of great importance in the marine activities. Estimation of the wave climate can be performed using three different sources of long term wave data, namely instrumentally measured, visually observed or numerically modeled data. Due to the lack of long term measurements, and the recent development of state of the art wind-wave models, nowadays numerically simulated wave data are widely used for determining the wave climate. However, the results of numerical wind-wave model generally contain some inherent errors due to a number of factors mainly inaccuracies in the forcing terms (Komen et al. 1994). The wind forcing in the wind wave models is generally produced by the numerical weather prediction models such as those operated at the ECMWF (European Center of Medium-range Weather Forecast). These numerically simulated wind data contain some inevitable errors that lead to inaccurate prediction of wind waves (Cavaleri and Bertotti 2004; Signell et al. 2005; Ardhuin et al. 2007). Therefore, data assimilation is used to reduce the model errors (Kantha and Clayson 2000; Babovic et al. 2005; Sannasiraj et al. 2006).

Different data assimilation procedures can be categorized to four main groups. Updating of input parameters, updating of state variables such as wave spectrum, updating of model parameters such as whitecapping dissipation rate and updating of output variables (error prediction) are the main data assimilation procedures (Refsgard 1997; Babovic et al. 2005). The last one is an appropriate method to improve the accuracy of the numerical models (Babovic et al. 2001). Since the numerical model errors are not the same for different output variables (Moeini and Etemad-Shahidi 2007), the last assimilation procedure can be used to modify different wave characteristics separately.

Emmanouil et al. (2010) employed Kalman filter in combination with Optimum Interpolation data assimilation scheme to improve forecasted wave heights in an open ocean area (southwest US coast). In this study, the Kalman filters were implemented in WAM model after the time integration of the two-dimensional frequency-direction wave spectra and before the data assimilation. The Kalman filter parameters were calculated based on the model predictions and the observations. Then, the correction effect of the Kalman filters was spread to a wider region by the use of a data assimilation system that follows the Kalman filters within the forecasting period. Their approach led to the extension of the assimilation impact to the whole forecasting period. A significant reduction of the magnitude and variability of the discrepancies between final forecasts and observations was achieved in this way (Emmanouil et al. 2010). Similar results are reported in Galanis et al. (2009) in that they employed some statistical tools to extend the impact of data assimilation on ocean wave prediction. In another study, Zhang et al. (2006) incorporated artificial neural networks and data assimilation techniques into the WAM model for wave forecasting. They assimilated altimeter significant wave height $\left(\mathrm{H}_{\mathrm{s}}\right)$ data into the wave model by the statistical interpolation method to improve the accuracy of wave height prediction. Then, artificial neural networks were employed to mimic the effect of data assimilation and applied to situations where altimeter wave data were not available. They showed that by applying this approach for wind-wave simulation in the South China Sea, an apparent improvement in the accuracy of the forecasting can be obtained. Sannasiraj et al. (2005) also employed local model for wave data assimilation in Taiwan. The local model in their study was built over the time series embedding theorem. They used WAM model for wave forecasting and compared their results with buoy measurements. In their study, the numerical model outputs were updated using error prediction approach by the local model. According to their results, using combination of numerical models and error prediction method reduces the errors of wave forecasting. Similar findings are reported by Babovic et al. (2005) and Sannasiraj et al. (2006). 
Some other researchers have studied wave data assimilation, especially altimetry data, into the numerical models. Skandari et al. (2005) evaluated the impact of using multisatellite of altimeter data to improve wave model analyses and forecasts at global scale. They employed the WAM model to generate significant wave height time series. They showed that the impact of data assimilation, when two or three sources of data are used instead of one, in term of significant wave height, is larger in wave model analyses but smaller in wave model forecasts. They also showed that there is no improvement in terms of wave periods, both in the analysis and forecast periods. Greenslade (2001) assimilated satellite altimeter significant wave height data into the AUSWAM model (a version of WAM), using a statistical interpolation scheme. He validated the results of his study against a number of waverider buoys situated around the Australian coast. He found that assimilation of the ERS-2 SWH data decreased the systematic bias in analyzed SWH by approximately $10 \%$ and the Scatter Index reduced by $6 \%$. The improvement in model skill was also retained throughout the forecast period. He showed that the assimilation has the greatest impact at locations on the west coast of Australia, where the sea-state is dominated by swell. Greenslade and Young (2005) developed models for the structure of the background errors in the wave data assimilation systems based on the results of previous studies. They tested their model in a global wave data assimilation system and the resulting wave forecasts were validated against observations from buoys. They showed that forecasts of significant wave height substantially improved, while forecasts of peak period were not similarly improved. Hasselmann et al. (1997) presented an optimal interpolation scheme for assimilating two-dimensional wave spectra. They showed that the correction of wind data needs to be combined with other data in an atmospheric data assimilation scheme. They emphasized the need for the development of combined wind and wave data assimilation schemes for the optimal use of satellite wind and wave data. Bender and Glowacki (1996) evaluated two strategies for the assimilation of wave heights into a spectral wave model. They assimilated satellite altimetry data from GEOSAT into the modeled wave data and showed a significant improvement in the wave prediction. Breivik and Reistad (1994) assimilated the observed significant wave height from ERS-1 in an operational numerical wave model. They compared their results with independent buoy measurement in the North Sea. They showed that the assimilation correction has an impact on 12-24h prognosis of the wave field. Dunlap et al. (1998), Young and Glowacki (1996) and Lionello et al. (1992) have also studied altimeter wave data assimilation into the wave models.

A few studies have been conducted on wave modeling in the Persian Gulf. Moeini et al. (2010) evaluated the quality of two sources of wind data, i.e. the ECMWF modeled winds and the measured data, for wave modeling in the Persian Gulf. They employed the third generation SWAN model for wave simulation and compared the results with one station recorded wave data. They found that the SWAN model overestimates the low wave heights and underestimates the higher ones because of the underestimation of high wind speeds by ECMWF. They also noted that the adaptation of the model parameters cannot lead to a comprehensive improvement of the model results. This implies the necessity of using more comprehensive methodologies, such as error prediction, for a more accurate prediction of all ranges of wave data. Taebi et al. (2008) simulated wind waves in the Persian Gulf and Gulf of Oman by Mike21 SW model forced by ECMWF wind data. They found that the hindcasted wave heights have the Scatter Index of nearly 40 percent after calibration of the model. Al-Salem et al. (2005) used third-generation WAM model to simulate the wind waves in the Persian Gulf with emphasis on Kuwait territorial waters. Wind data with a spatial resolution of $0.5^{\circ}$ obtained from the ECMWF was used to force the model. The model was validated using measured waves at several locations in Kuwait waters. It was shown that the WAM model successfully predicts the wave conditions except for some storms where the value of $H_{s}$ is underestimated. This underestimation was due to the underestimation of the storms by ECMWF. Similar results can be found in Rakha et al. (2007).

The main goal of this study is to improve the simulation of wind waves in the Persian Gulf using error prediction approach. Hence, the SWAN model (Booij et al. 1999) was 
employed for wave hindcasting and reproducing time series of wave data. The model outputs were compared with field measurements at two stations to verify the results. After wave simulation by the SWAN model, artificial neural network was used to improve the results of wave modeling based on the modelled and measured data. The use of error prediction approach and updating of output variables has several advantages compared to other assimilation methods. At first, it can be used to improve different output variables such as wave height and period separately. Secondly, a wider range of output data can be improved using this method (Moeini et al. 2010). Finally, this assimilation approach will cover almost all of the error sources including forcing terms and wave model evolution.

It is worth noticing that using neural networks without combination with numerical model for wave prediction has some limitations. Since this method is generally appropriate for interpolation rather than extrapolation, the available data for learning process should cover all range of the probable events in the study area. Therefore, it may not be suitable for the prediction of extreme events. In addition, when this method is used for wave forecasting, the potential forecast horizon is typically quite short (Agrawal and Deo 2002).

This paper is organized as follows. Section 2 introduces the study area and the field data. Section 3 gives a brief description of the SWAN model and error prediction technique, and the results and discussions are described in Section 4. Finally, Section 5 covers the summary and conclusions.

\section{Study area and the used data}

The Persian Gulf, located in the southwest of the Asian continent is a shallow, semienclosed basin in a typical arid zone and is an arm of the Indian Ocean. It is located between the longitude of $48-57^{\circ} \mathrm{E}$ and the latitude of $24-30^{\circ} \mathrm{N}$ (Fig. 1). This Gulf is connected to the deep Gulf of Oman through the narrow Strait of Hormuz. The Persian Gulf covers an area of approximately 226,000 $\mathrm{km}^{2}$ with a length of $990 \mathrm{~km}$. Its width varies from 56 to $338 \mathrm{~km}$, separating Iran from the Arabian Peninsula with the shortest distance of about $56 \mathrm{~km}$ in the Strait of Hormuz. This basin has an average depth of about $35 \mathrm{~m}$ and the deepest water depth is approximately $107 \mathrm{~m}$ (Purser and Seibold 1973; Emery 1956).

In the present study, two sets of recorded wave data were used for verification of the results. The first recorded wave data set was collected by a surface buoy located in $50.7^{\circ}$ $\mathrm{E}$ and $28.9^{\circ} \mathrm{N}$ near Bushehr port (hereinafter called Bushehr station). The water depth in the location of buoy was nearly $27 \mathrm{~m}$ (Fig. 1). The wave data were recorded from the first of February, 1995 until 31st December, 1996. The second measured station was located at $48.167^{\circ} \mathrm{E}$ and $29.167^{\circ} \mathrm{N}$ in the Kuwait territorial waters (Fig. 1). The wave data were recorded 3-hourly from the first of January, until 30st August, 1994. This measurement station is called Kuwait station hereinafter. Each set of wave data was divided randomly to three parts, i.e. training, testing and validation data.

The wind data used were the 6-hourly $10 \mathrm{~m}$ operational ECMWF data with a spatial resolution of $0.5^{\circ}$. It should be noted that ECMWF operational was selected because of its higher spatial resolution than that of ECMWF re-analysis (1.125 spatial resolution).

\section{Numerical model and error prediction technique}

In this study, the third generation spectral SWAN model (Booij et al. 1999) was employed to simulate wind waves over the Persian Gulf. The SWAN model is a spectral wind wave model, developed to obtain reliable estimates of wave parameters in coastal waters. In this model, action density spectrum is considered rather than energy density spectrum because it is conserved in the presence of currents unlike energy density. The action density is the energy density divided by the relative frequency: 


$$
\mathrm{N}(\sigma, \theta)=\mathrm{E}(\sigma, \theta) / \sigma
$$

The relative frequency $\sigma$ and the wave direction $\theta$ are the independent variables. In this model the wave spectrum evolution in the space $(\mathrm{x}, \mathrm{y})$ and time $(\mathrm{t})$ is described by the spectral action balance equation (Booij et al. 1999). In the present study, SWAN cycle III version 40.72 (The SWAN Team 2007) was used for wave simulation. The SWAN model was executed in nonstationary mode and spherical coordinates. Since the Komen's formulation for wind input parameterization (Komen et al. 1984) leads to better results (Moeini and Etemad-Shahidi 2007), this formulation was used for exponential growths of wind input. Additionally, quadruplet wave interaction was activated for nonlinear interaction. Dissipation due to bottom friction, whitecapping and depth-induced wave breaking were considered in the simulation. The geographical space was discretized into $200 \times 160$ cell grid over the Persian Gulf (Fig. 1 ) with a $0.05 \times 0.05$ degree resolution in $x$ and y directions. The spectral space was divided into 20 logarithmically spaced frequencies, from 0.06 to $1 \mathrm{~Hz}$ and 24 equal directions in the rose $(\Delta \theta=360 / 24=15)$. This depicts that the lowest period of the simulated waves is 1 second and the highest was nearly 17 seconds covering typical wind waves in the Persian Gulf. The computational time step was set as 10 minutes as well.

In the recent decades, artificial neural networks (ANNs) have been widely used in the ocean and coastal engineering applications especially wind and wave modeling (Agrawal and Deo 2002; Makarynskyy et al. 2005). The deviations between the simulations and the measured values, i.e. the model errors, are usually serially correlated. Therefore, it is possible to predict the values of these errors by means of time series models such as autoregressive moving average model or neural networks. The simulations can then be improved by adding the error predictions. This method, which is often referred to as error prediction, has been used in the real time forecasting (Refsgard 1997, Babovic et al. 2001, Babovic et al. 2005). In the present study, a two-layer feed-forward network with the sigmoid hidden neurons and linear output neurons was employed for error prediction of the wave modeling. The network was trained with Levenberg-Marquardt backpropagation algorithm. The possible inputs of the ANN for error prediction of wave modeling at the current time step (analysis time) are the mean wind speed, mean wind direction, wind duration, fetch length, the modeled $\mathrm{H}_{\mathrm{s}}, \mathrm{T}_{\mathrm{m}}$ and mean wave direction. Separated networks were employed for error estimation at each wave measurement station. To determine the wind duration, definition of constant wind presented in the CEM (US army 2006) was used. In this way, a constant wind is defined when the difference between the current wind speed and mean wind speed at previous time steps does not exceed a certain value (i.e. $2.5 \mathrm{~ms}^{-1}$ ). In addition, wind direction should not vary more than 45 degrees. The presented data assimilation algorithm can be also used for future time steps. More details about neural network modeling can be found in Agrawal and Deo (2002).

\section{Results and discussion}

\subsection{Simulation}

To investigate the performance of assimilation techniques, firstly all model parameters were set as default. Figure 2 shows time series of measured and modeled significant wave heights and mean wave periods during November, 1995 at Bushehr station. Figure 3 shows the mentioned parameters at Kuwait station during January, 1994. As seen in Fig. 2, high waves are generally underestimated by the SWAN model at Bushehr station mainly due to the underestimation of driving wind field (Moeini et al. 2010). The wave periods are significantly underestimated at this station. Comparison of the results at Kuwait station (Fig. 3) shows that $\mathrm{H}_{\mathrm{s}}$ are well predicted by the model except for some storms where they are underestimated. The wave periods are underestimated generally at 
this station too. As seen in tables 1 and 2, the RMSE of the prediction of significant wave height at Bushehr station is nearly two times of that for Kuwait station. The scatter index of the prediction of significant wave height at Bushehr station is almost 11 percent more than that of Kuwait station. The wave period is underestimated about 1 second at Bushehr station and half a second at Kuwait station. These findings are in agreement with those of Rakha et al. (2007) showing the underestimation of some modeled $\mathrm{H}_{\mathrm{s}}$ by WAM model in Kuwait waters. These results show that the model errors are not the same for wave height and period because of the wave model evolution (Lin et al. 2002; Moeini and EtemadShahidi 2007).

\subsection{Data assimilation}

After assessment of the wave model, the model parameters were updated to evaluate their effects on the improvement of the results. In this step, the whitecapping dissipation rate was used as the tunable parameter. Other physical parameters such as bottom friction and wave breaking had no significant effect on the model results because of the deep water location of the buoys. The focus of this step was on the improvement of the wave height at Iranian waters, i.e. Bushehr station. The whitecapping dissipation rate was finally reduced about 70 percent. Figures 2 and 3 also depict the qualitative comparisons of the hourly time series of the modeled $\mathrm{H}_{\mathrm{s}}$ and mean wave period $\left(\mathrm{T}_{\mathrm{m}}\right)$ using the updated parameter.

As seen in Fig. 2, updating of the model parameter leads to greater consistency between modeled and measured $\mathrm{H}_{\mathrm{s}}$ especially in case of high waves at Bushehr station. However, some inconsistencies are observed between the measured and modeled wave heights because of inaccuracies in the forcing terms. In this case, low waves are generally overestimated. Similar results can be found in Moeini et al. (2010) for another area in the Persian Gulf. It is worth noticing that the wave periods are still underestimated at this station after adaptation of the model parameter based on the modeled wave height. The effect of updating of the model parameter on the modeled wave data at Kuwait station is shown in Fig. 3. This figure shows that updating of the model parameter based on the modeled wave height at Bushehr station results in the overestimation of wave heights at Kuwait station. This fact reveals that spatial error of the output variables is not uniformly distributed probably due to the spatially nonuniform error covariance of the wind input, since the error in the modeled waves is mainly due to the wind forcing error (Komen at al. 1994). In spite of general overestimation of the modeled $H_{s}$ at Kuwait station, Fig. 3 also shows that wave period is underestimated in this condition. These findings show that owing to the difference between accuracy of the model for prediction of wave height and period, adaptation of the model parameter leads only to improvement in one variable. In other words, by updating of the model parameter different output variables cannot be improved simultaneously. On the other hand, adaptation of the model parameters can only enhance the results of one wave characteristic up to a certain level, depending on the accuracy of the wind input. These shortcomings in this data assimilation technique justify the necessity of employing more comprehensive methodologies, such as error prediction, for a more accurate prediction of all ranges of different wave parameters. Therefore, updating of output variables $\left(\mathrm{H}_{\mathrm{s}}\right.$ and $\left.\mathrm{T}_{\mathrm{m}}\right)$ was considered in the next step for further improvement in the results.

In this step, ANN was employed to improve the model results. Different approaches were employed to predict the correct values of the wave parameters. In the first approach, the error predictions were combined with the modeled values. The error of the modeled parameters, i.e. $H_{s}$ and $T_{m}$, were estimated by ANN. In the second approach, the wave parameters were predicted directly by ANN. It will be shown that combination of the ANN estimated error with modeled wave parameter leads to more accurate results than prediction of the wave parameters by ANN. Let X be the wave parameter, i.e. the $\mathrm{H}_{\mathrm{s}}$ or $\mathrm{T}_{\mathrm{m}}$. The error of the wave prediction can be defined as

$$
\mathrm{E}_{\text {modeled }}=\mathrm{X}_{\text {measured }}-\mathrm{X}_{\text {modeled }}
$$


where $X_{\text {modeled }}$ is the modeled wave parameter (by the SWAN) and $X_{\text {measured }}$ is the corresponding measured value. If $\mathrm{E}_{\text {modeled }}$ can be estimated by ANN, then the modified wave parameter can be obtained by

$$
\mathrm{X}_{\text {modified }}=\mathrm{X}_{\text {modeled }}+\mathrm{E}_{\text {predited }}
$$

where $E_{\text {predicted }}$ is the estimated error of the wave parameter modelled by ANN. To determine the effective input parameters and the best topology, different networks with various combinations of input parameters were considered. The wind speed, wind direction, wind duration, wind shear velocity, modeled wave height, period and direction were tested as the network inputs. It was revealed that the best inputs for the error prediction network of the $\mathrm{H}_{\mathrm{s}}$ are the mean wind speed, mean wind direction, wind duration and the modeled $\mathrm{H}_{\mathrm{s}}$. For the error prediction network of the $\mathrm{T}_{\mathrm{m}}$, the modeled wave height was replaced with the modeled wave period. The assessment of the best inputs was performed based on the sensitivity analysis and error statistics of the results. The numerically modeled wave parameters have an important role in the error prediction approach that will be discussed later.

Figures 4 and 5 illustrate the comparison of time series of the updated wave parameters using ANN against the measurements at Bushehr and Kuwait stations, respectively. In contrast to Fig. 2 and 3, it can be seen that combination of the SWAN numerical model and ANN leads to better improvements in the wave simulation rather than updating of the model parameter. As seen, both the updated wave heights and periods follow the measurements very well. In addition, there is a great consistency between the measured and updated wave data for both low and high values. In other words, the employed assimilation approach successfully covers the error sources of the simulation and results in the improvement in a wider range of output variables. To have an overall assessment of the employed approaches, the scatter diagrams of $\mathrm{H}_{\mathrm{s}}$ and $\mathrm{T}_{\mathrm{m}}$ are depicted in Fig. 6 and 7. In addition, Tables 1 and 2 show the summary of error measures (Bias, RMSE, Scatter Index and $\mathrm{R}^{2}$ ) at Bushehr and Kuwait stations for the whole time period that wave data were available. According to Fig. 6 and Table 1, the wave heights at Bushehr station modeled by SWAN with default parameter are underestimated (Bias: $-0.06 \mathrm{~m}$ ) and have a large scatter (Scatter Index: $65.19 \%$ ). After updating of the model parameter, the modeled wave heights become overestimated (Bias: $0.16 \mathrm{~m}$ ), but the Scatter Index increases. These statistics were computed based on the all range of wave data. Because of the importance of high waves, updating of the model parameter was conducted based on the simulation of high waves. Since the ECMWF wind data are underestimated especially for high values, the calibration of high values has led to the overestimation of low wave heights (Moeini et al. 2010). Therefore, the statistics for all range of wave data after updating of the model parameter are worse than those before that. As an example, the SI (for the measured wave height larger than 1 meter) was about $48 \%$ before updating of the model parameter and it was reduced to $32 \%$ after updating.

The best results are obtained in the third approach that is the combination of error prediction by ANN and SWAN outputs. In this case, the simulated wave heights have no Bias and the Scatter Index is significantly decreased (Scatter Index: $20.2 \%$ ). In the case of $\mathrm{T}_{\mathrm{m}}$, the Scatter Index decreases about $80 \%$ after using error prediction approach. Similar results are observed for Kuwait station (Fig. 7 and table 2). In this station, the scatter index decreases about $69 \%$ for wave height and $75 \%$ for wave period after combination of ANN and numerical model. These findings show that the output updating approach outperforms updating of the model parameters, which is in line with the results of Babovic et al. (2007) and Sannasiraj et al. (2005).

As mentioned before, Different approaches were employed to predict the correct values of the wave parameters. The measured and modeled wave parameters at Bushehr station in January were analyzed. At first, ANN was employed to estimate measured wave parameters. Secondly, error prediction approach was considered. Table 3 represents the statistical analysis of the predicted wave parameters in this period. As seen, the Scatter Index of predicted wave height decreases about $11 \%$ using error prediction approach 
compared with that of prediction of the correct $\mathrm{H}_{\mathrm{s}}$ using ANN. In the case of $\mathrm{T}_{\mathrm{m}}$, error prediction method results in a decrease of about $29 \%$ in the Scatter Index compared with that of $\mathrm{T}_{\mathrm{m}}$ prediction by ANN.

Finally, it is worth noticing that the numerical wave modeling has an important role in the employed approach. The modeled wave parameters contain valuable information that is very important in the estimation of errors. In addition to wind forcing parameters, the error of the predictions depends on the modeled parameter as well. To reveal this fact, two different networks were considered. The inputs of the first network were the mean wind speed, mean wind direction and wind duration. For the second networks, the modeled $H_{s}$ and $T_{m}$ were added to the networks inputs for error prediction of the wave height and period, respectively. Table 3 shows the results of this assessment at Bushehr station in January. As seen, a significant reduction in the Scatter Index of the predicted wave height is observed after adding the modeled $\mathrm{H}_{\mathrm{s}}$ to the networks input. In this case, the Scatter Index shows an improvement of about $43 \%$. In the case of $\mathrm{T}_{\mathrm{m}}$, a reduction of about $31 \%$ in the Scatter Index of predicted $\mathrm{T}_{\mathrm{m}}$ is seen where the Scatter Index decreases from $9.21 \%$ to $6.34 \%$. This is mainly due to the fact that the wind field error depends also on the dynamics of wind-wave system and modeling of drag in the surface layer. In addition, waves are an integrated effect of the driving wind fields in space and time (Cavaleri and Bertotti 1997). Thus, it is suggested to use the employed approach for determining long-term time series of wave characteristics in the Persian Gulf.

The low number of wave measurement stations and the relatively short recording period may be the drawbacks of the present study. In addition, discovering the error distribution of the ECMWF winds and the modeled waves over the domain is also a matter of interest. Thus, it is recommended that more measured data such as satellite observations be employed for spatial assessment of the modeled wind and wave data.

\section{Summary and conclusions}

In this study an efficient approach for the assimilation of the hindcasted wave parameters in the Persian Gulf was developed. To do so, the third generation SWAN model was employed for wave simulation forced by the 6-hourly ECMWF wind data with a resolution of $0.5^{\circ}$. In-situ wave measurements in two stations were utilized for the evaluation of the studied approaches. Two main data assimilation procedures i.e. updating of model parameters and updating of output variables were analyzed for nudging the modeled data to the real one. Updating of output variables was carried out by means of ANN for estimation of the deviations between the simulated and measured wave characteristics. Different networks with various combinations of input parameters were considered to determine the effective input parameters and the best combination. The most important results are summarized as follows:

The model errors are not the same for wave height and period mainly due to the wave model evolution. Therefore, adaptation of the model parameter results in the improvement in only one output variable. In other words, by updating of the model parameter different output variables cannot be improved simultaneously. Additionally, even for one variable, adaptation of the model parameters can enhance the results up to a certain level depending on the accuracy of the wind input. Large scatter between modeled and measured data may still exist using this approach.

Updating of output variables outperforms updating of the model parameters for data assimilation. In this approach, both updated wave height and period follow the measurements very well. In addition, this assimilation approach covers almost all of the error sources of the wave modeling and results in the improvement of low and high values of output variables.

Combination of the ANN estimated error with numerically modeled wave parameters leads to better improvement in the predicted wave data in contrast to direct estimation of the desired parameters by ANN. In addition, the best inputs are the mean wind speed, mean wind direction, wind duration and the modeled wave parameters. The modeled 
wave parameters, as the network inputs, increase the accuracy of the error estimation significantly.

\section{Acknowledgements}

We acknowledge the Iranian National Institute for Oceanography, the Iranian Meteorological Office and the Iranian National Cartographic Center for providing the used data. We would also thank the SWAN group at the Delft University of Technology (Department of Fluid Mechanics) for providing the wave model. We also express our gratefulness to Dr K. Rakha and Dr. S. Neelamani from Kuwait Institute for Scientific Research for their help. This study was supported by the Transportation Research Institute, Tehran, I.R. Iran, grant no. 89B8T8P09. 


\section{References}

Agrawal JD, Deo MC (2002) On-line wave prediction. Marine Structures 15: 57-74.

Al-Salem K, Rakha KA, Sulisz W, Al-Nassar W (2005) Verification of a WAM model for the Arabian Gulf. In: Proceedings of the Arabian Coast 2005 Conference, Dubai.

Ardhuin F, Bertotti L, Bidlot JR, Cavaleri L, Filipetto V, Lefevre JM, Wittmann P (2007)

Comparison of wind and wave measurements and models in the Western Mediterranean Sea.

Ocean Eng 34: 526-541. doi:10.1016/j.oceaneng.2006.02.008

Babovic V, Sannasiraj SA, Chan ES (2005) Error correction of a predictive ocean wave model using local model approximation. Marine Syst 53: 1- 17. doi:10.1016/j.jmarsys.2004.05.028

Babovic V, Canizares R, Jensen HR, Klinting A (2001) Neural networks as routine for error updating of numerical models. ASCE, J Hydraulic Eng 127(3):181-193.

Bender LC, Glowacki T (1996) The assimilation of altimeter data into the Australian wave model. Aust. Meteorol. Mag. 45: 41- 48.

Booij N, Ris RC, Holthuijsen LH (1999) A third generation wave model for coastal regions. 1. Model description and validation. J Geophys Res 104: 7649-7666.

Breivik LA, Reistad M (1994) Assimilation of ERS-1 altimeter wave heights in an operational numerical wave model. Weather and Forecasting 9: 440-451.

Cavaleri L, Bertotti L (1997). In search of the correct wind and wave fields in a minor basin. Mon Weather Rev 125(8): 1964-1975.

Cavaleri L, Bertotti L (2004) Accuracy of the modelled wind and wave fields in enclosed seas. Tellus 56 A: $167-175$.

Dunlap EM, Olsen RB, Wilson L, De Margerie S, Lalbeharry R (1998) The effect of assimilating ERS-1 fast delivery wave data into the North Atlantic WAM model. J. Geophys Res 103(C4): 7901- 7915. doi: 10.1029/97JC02570

Emmanouil G, Galanis G, Kallos G (2010) A new methodology for using buoy measurements in sea wave data assimilation. Ocean Dyn 60: 1205-1218. doi: 10.1007/s10236-010-0328-9

Emery KO (1956) Sediments and water of the Persian Gulf. Bulletin of the American Association of Petroleum Geologists 40(10): 2354-2383.

Galanis G, Emmanouil G, Chu PC, Kallos G (2009) A new methodology for the extension of the impact of data assimilation on ocean wave prediction. Ocean Dyn 59: 523-535. doi:

10.1007/s10236-009-0191-8

Greenslade DJM (2001) The assimilation of ERS-2 significant wave height data in the Australian region. J. Mar. Syst. 28: 141- 160.

Greenslade DJM, Young IR (2005) The impact of inhomogenous background errors on a global wave data assimilation system. J. Atmos. Oc. Sci. 10(2): 61-93. doi: 10.1080/17417530500089666 Hasselmann S, Lionello P, Hasselmann K (1997) An optimal interpolation scheme for the assimilation of spectral wave data. J. Geophys Res 102(C7): 15823- 15836.

Kantha LH, Clayson CA (2000) Numerical models of oceans and oceanic processes. Academic Press, California.

Komen GJ, Hasselmann S, Hasselmann K (1984) On the existence of a fully developed wind sea spectrum. J Phys Oceanogr 14: 1271-1285. 
Komen GJ, Cavaleri L, Donelan M, Hasselmann K, Hasselmann S, Janssen PAEM (1994)

Dynamics and modelling of ocen waves. Cambridge University Press, Cambridge.

Lin W, Sanford LP, Suttles SE (2002) Wave measurement and modeling in Chesapeake Bay.

Continental Shelf Res 22: 2673-2686.

Lionello P, Gunther H, Janssen P AEM (1992) Assimilation of altimeter data in a global thirdgeneration wave model. J. Geophys Res 97(C9): 14453- 14474.

Makarynskyy O, Pires-Silva AA, Makarynska D, Ventura-Soares C (2005) Artificial neural networks in wave predictions at the west coast of Portugal. Comput Geosci 31(4): 415-24.

Moeini MH, Etemad-Shahidi A (2007) Application of two numerical models for wave hindcasting in Lake Erie. Appl Ocean Res 29: 137-145. doi:10.1016/j.apor.2007.10.001

Moeini MH, Etemad-Shahidi A, Chegini V (2010) Wave modeling and extreme value analysis off the northern coast of the Persian Gulf. Appl Ocean Res 32: 209-218.

doi:10.1016/j.apor.2009.10.005

Purser BH, Seibold E (1973) The principal environmental factors influencing Holocene sedimentation and diagenesis in the Persian Gulf. Persian Gulf, Berlin, 1-9.

Rakha KA, Al-salem K, Neelamani S (2007) Hydrodynamic atlas for Kuwaiti territorial waters. Kuwait Journal of Science and Engineering 34: 143-156.

Refsgard JC (1997) Validation and intercomparison of different updating procedures for real-time forecasting. Nordic Hydrol. 28: 65-84

Sannasiraj SA, Babovic V, Chan E S (2005). Local model approximation in the real time wave forecasting. Coast Eng 52: 221-236. doi:10.1016/j.coastaleng.2004.12.004

Sannasiraj SA, Babovic V, Chan ES (2006) Wave data assimilation using ensemble error covariances for operational wave forecast. Ocean Model 14: 102-121.

doi:10.1016/j.ocemod.2006.04.001

Signell RP, Carniel S, Cavaleri L, Chiggiato J, Doyle JD, Pullen J, Sclavo M (2005) Assessment of wind quality for oceanographic modelling in semi-enclosed basins. J Marine Syst 53: 217- 233. doi:10.1016/j.jmarsys.2004.03.006

Skandrani C, Lefevre J-M, Queffeulou P (2005) Impact of multi-satellite altimeter data assimilation on wave analysis and forecast. Marine Geodesy 27: 511-533.

Taebi S, Golshani A, Chegini V (2008) An approach towards wave climate study in The Persian Gulf and the Gulf of Oman: simulation and validation. J Marine Eng 4(7): 11-26.

The SWAN team (2007) SWAN User Manual (Cycle III version 40.51). Delft University of Technology, Delft

US Army (2006). Coastal Engineering Manual, Chapter II-2, Meteorology and Wave Climate. Engineer Manual 1110-2-1100. US Army Corps of Engineers, Washington, DC.

Young IR, Glowacki TJ (1996) Assimilation of altimeter wave height data into a spectral wave model using statistical interpolation. Ocean Eng. 23(8): 667- 689. doi: 10.1016/0029-

$\underline{\text { 8018(95)00066-6 }}$

Zhang Z, Li CW, Qi Y, Li YS (2006) Incorporation of artificial neural networks and data assimilation techniques into a third-generation wind-wave model for wave forecasting. $\mathrm{J}$ Hydroinformatics 08.1: 65-76. doi: 10.2166/jh.2006.005 


\section{Figure's Caption:}

Fig. 1 The Persian Gulf, modeled area and wave measurement stations

Fig. 2 Comparison of the modeled wave heights and periods with default and updated parameter against the measurements at Bushehr station

Fig. 3 Comparison of the modeled wave heights and periods with default and updated parameter against the measurements at Kuwait station

Fig. 4 Comparison of the updated modeled wave heights and periods by ANN against the measurements at Bushehr station

Fig. 5 Comparison of the updated modeled wave heights and periods by ANN against the measurements at Kuwait station

Fig. 6 Scatter diagrams of the significant wave height (left panel) and wave period (right panel) at Bushehr station (A) SWAN model with default parameter (B) SWAN model with updated parameter (C) modified wave characteristics by ANN

Fig. 7 Scatter diagrams of the significant wave height (left panel) and wave period (right panel) at Kuwait station (A) SWAN model with default parameter (B) SWAN model with updated parameter (C) modified wave characteristics by ANN 


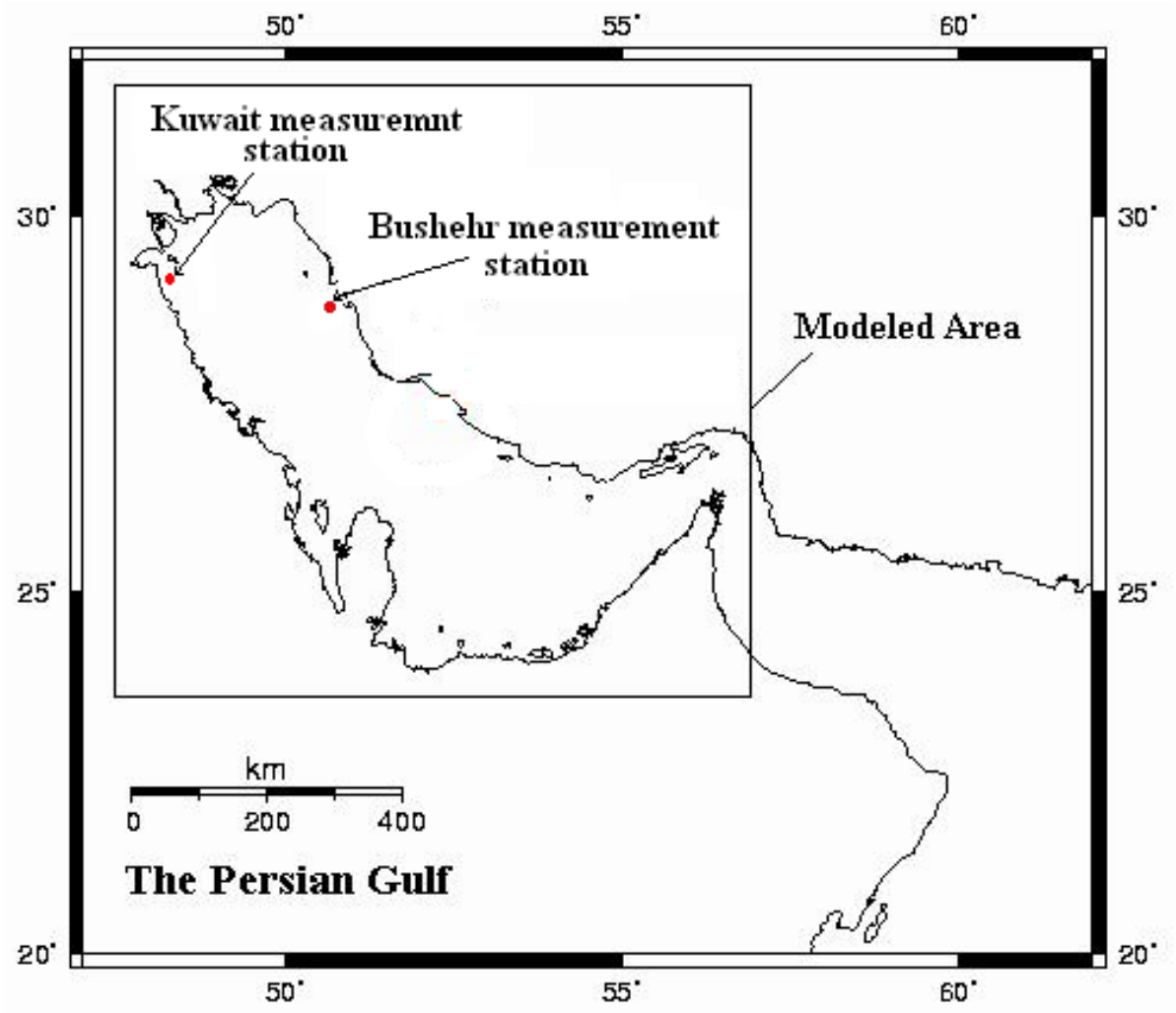

Fig. 1 The Persian Gulf, modeled area and wave measurement stations 

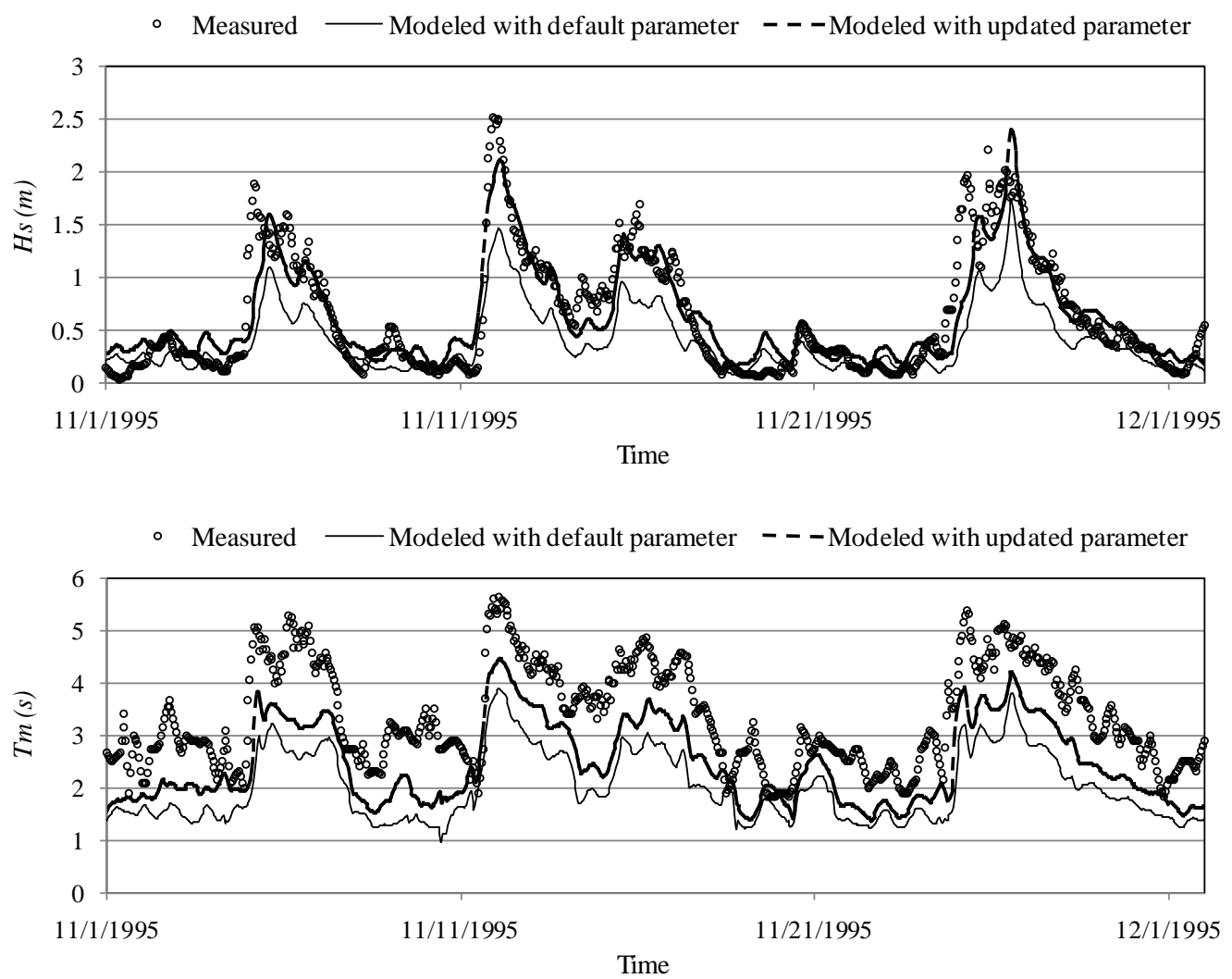

Fig. 2 Comparison of the modeled wave heights and periods with default and updated parameter against the measurements at Bushehr station 
- Measured — Modeled with default parameter - - - Modeled with updated parameter

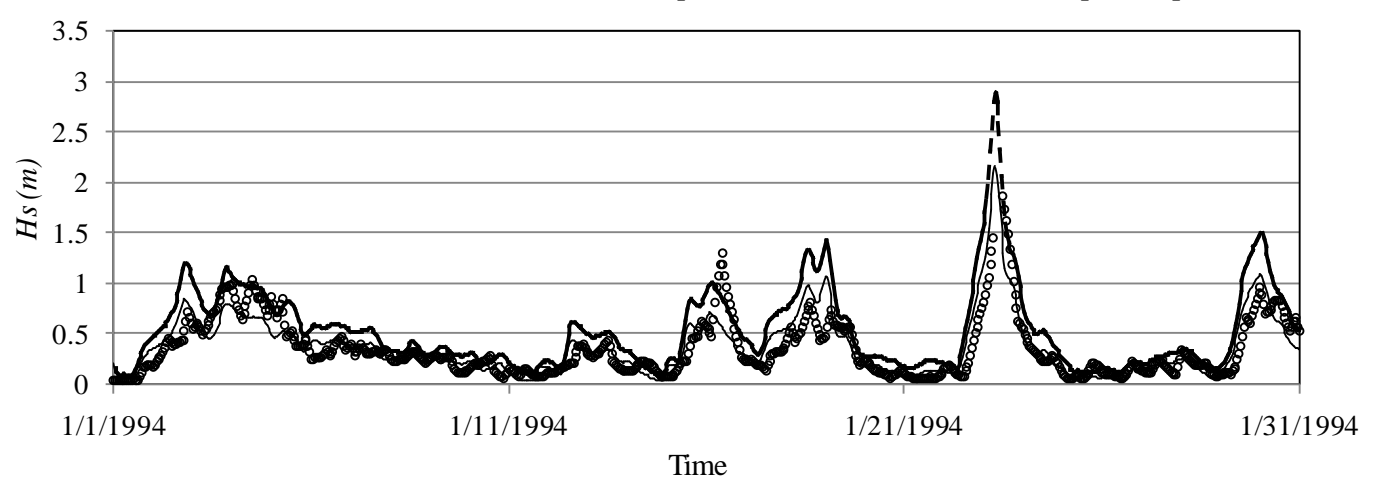

- Measured — Modeled with default parameter _ - - Modeled with updated parameter

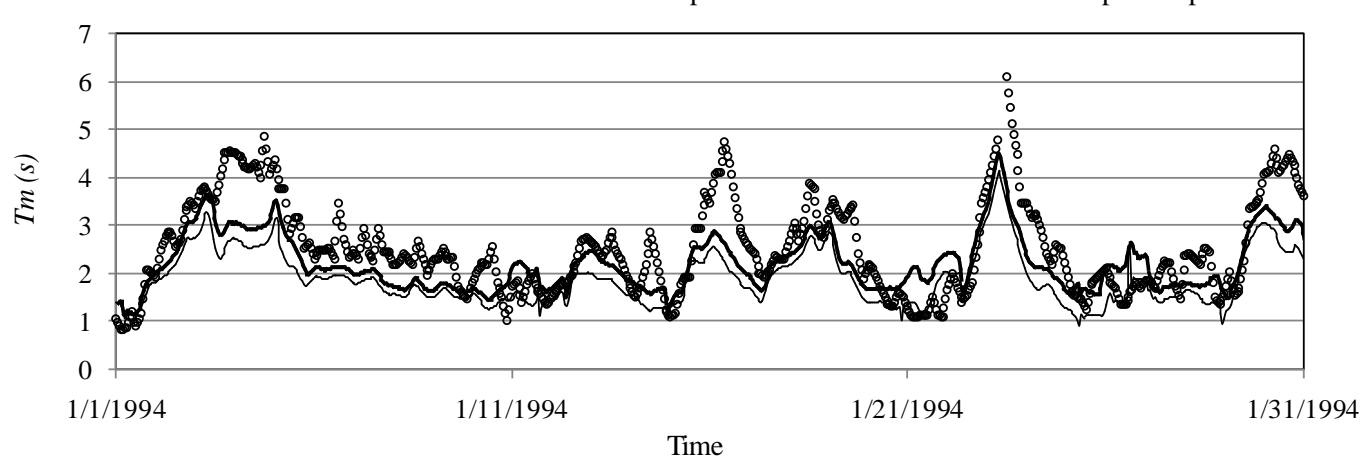

Fig. 3 Comparison of the modeled wave heights and periods with default and updated parameter against the measurements at Kuwait station 

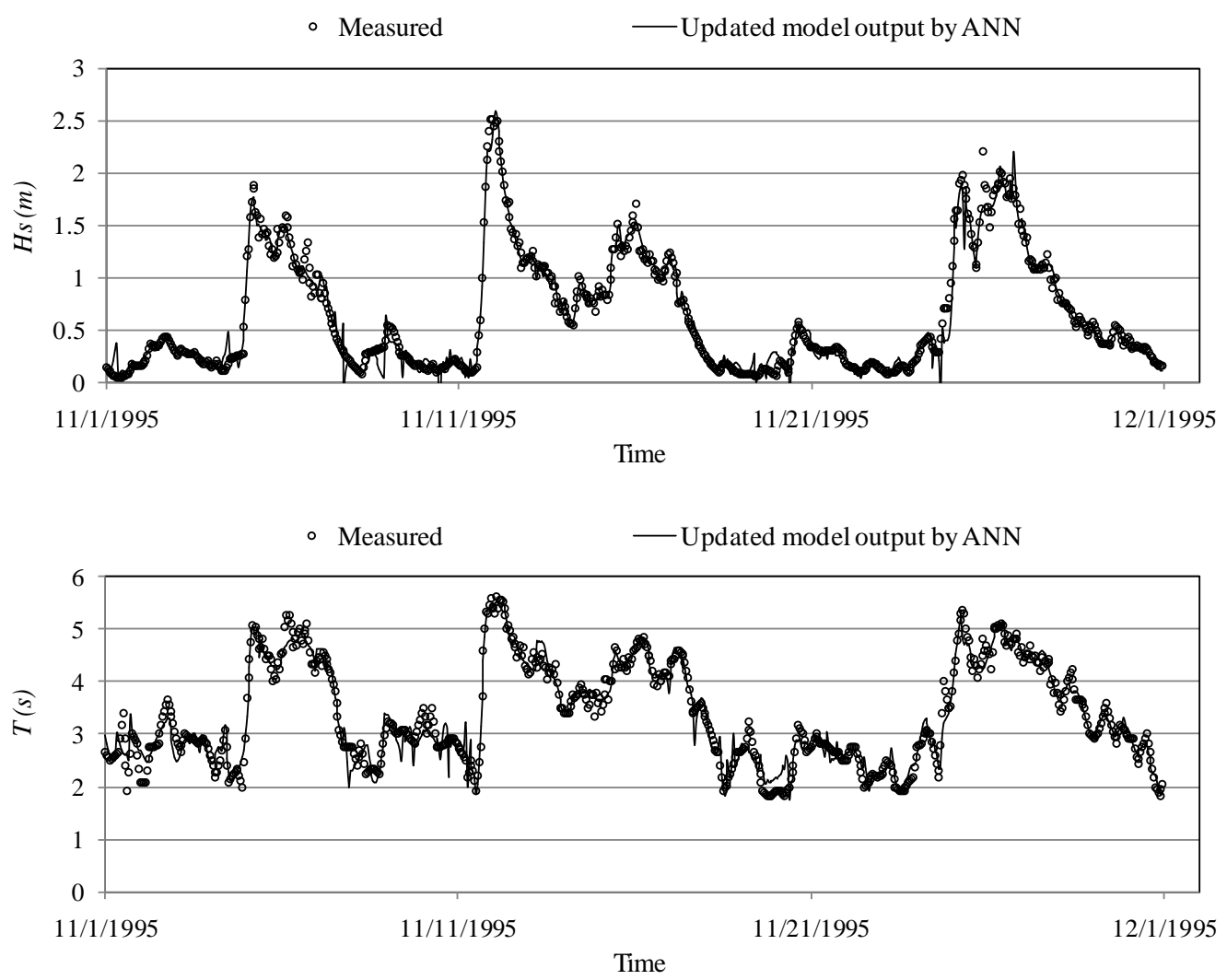

Fig. 4 Comparison of the updated modeled wave heights and periods by ANN against the measurements at Bushehr station 


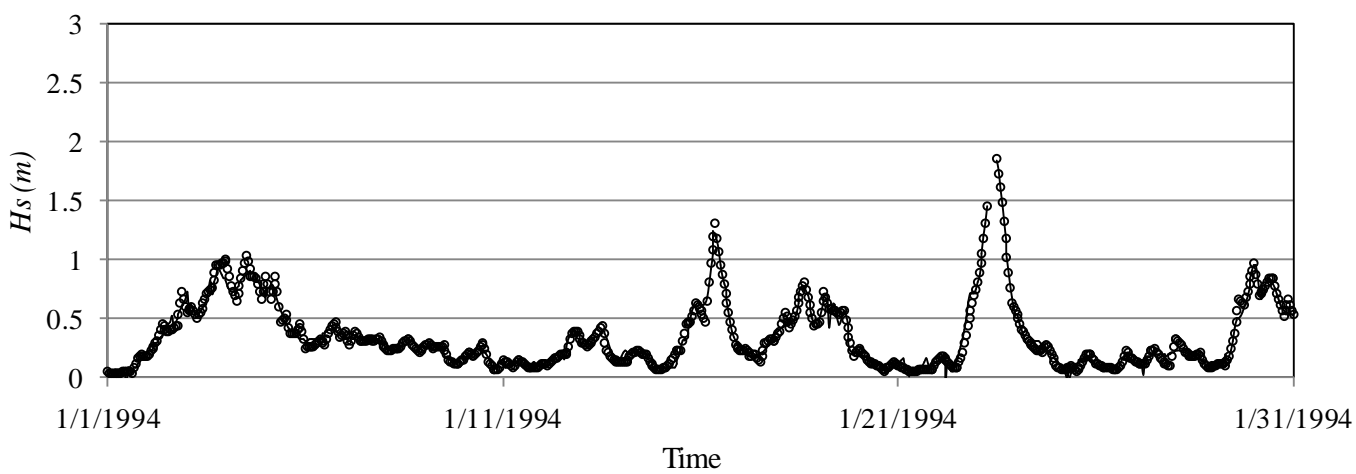

- Measured —Updated model output by ANN

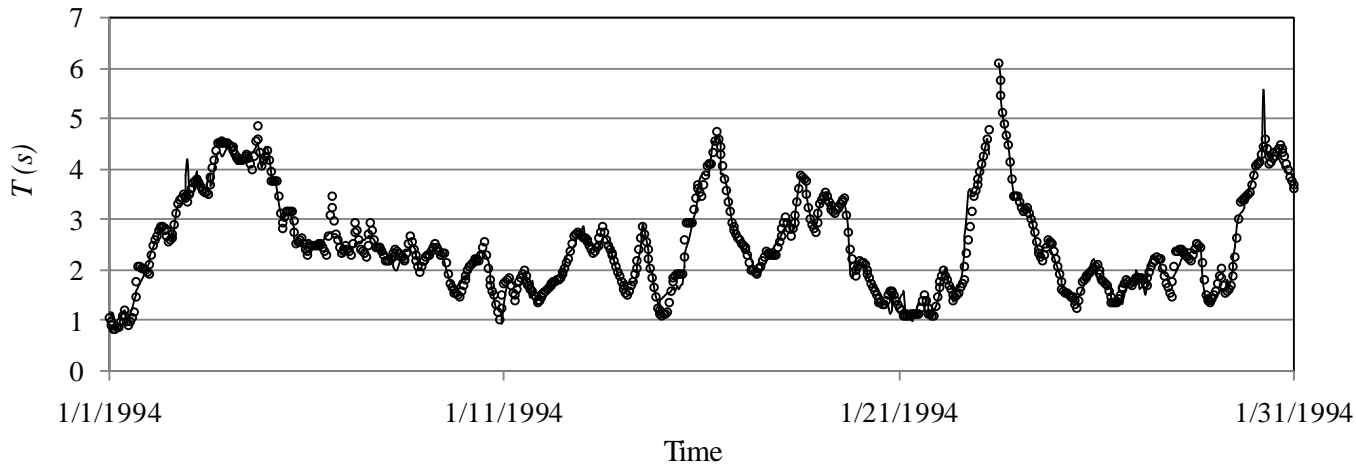

Fig. 5 Comparison of the updated modeled wave heights and periods by ANN against the measurements at Kuwait station 


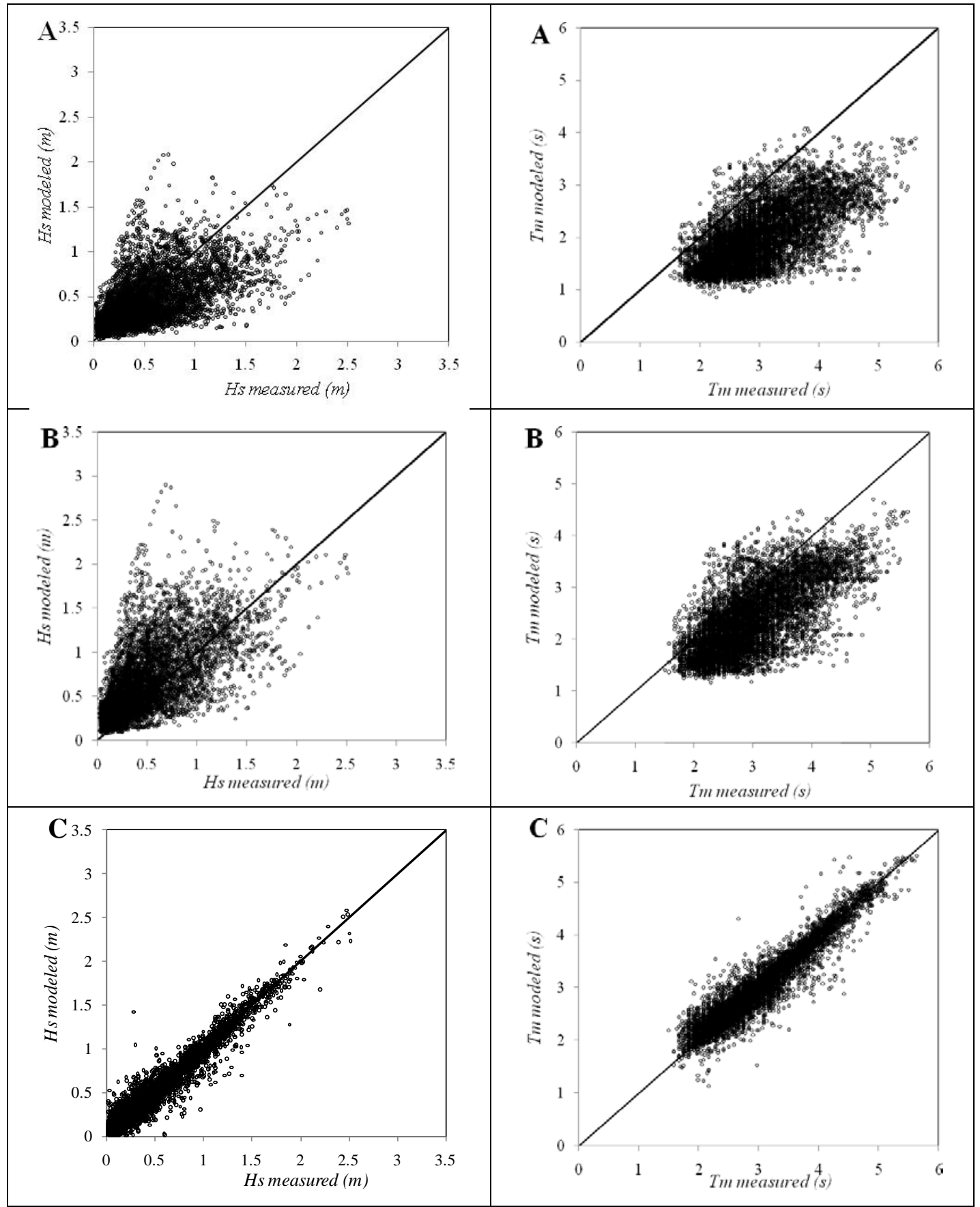

Fig. 6 Scatter diagrams of the significant wave height (left panel) and wave period (right panel) at Bushehr station (A) SWAN model with default parameter (B) SWAN model with updated parameter (C) modified wave characteristics by ANN 


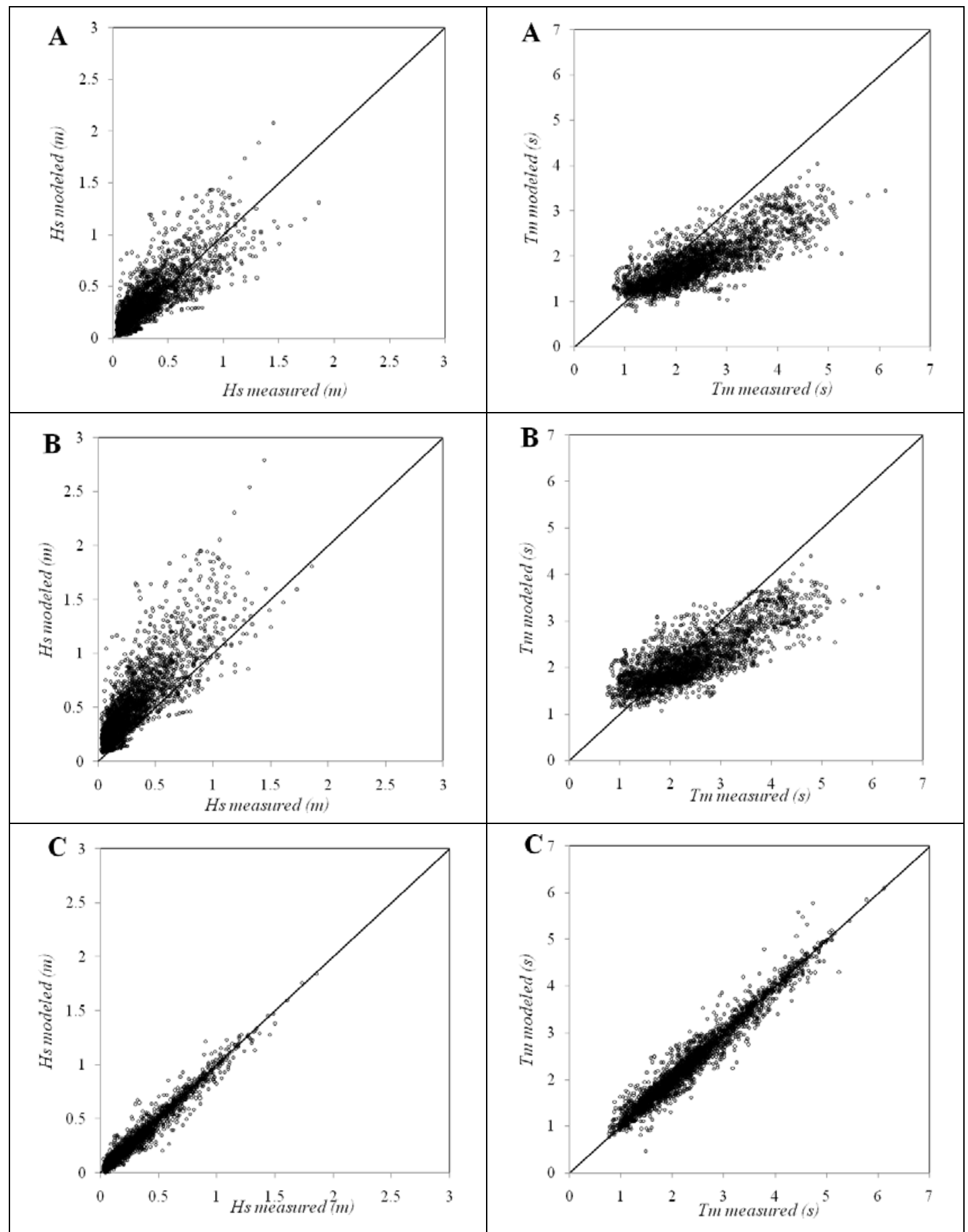

Fig. 7 Scatter diagrams of the significant wave height (left panel) and wave period (right panel) at Kuwait station (A) SWAN model with default parameter (B) SWAN model with updated parameter (C) modified wave characteristics by ANN 
Table 1 The summary of statistical analysis of wave prediction in the analyzed scenarios for

Bushehr station

\begin{tabular}{|c|c|c|c|c|}
\hline $\begin{array}{c}\text { Wave } \\
\text { characteristics }\end{array}$ & Statistical Parameter & $\begin{array}{c}\text { Modeled by } \\
\text { default parameter }\end{array}$ & $\begin{array}{c}\text { Modeled by } \\
\text { updated parameter }\end{array}$ & $\begin{array}{c}\text { modified } \\
\text { by ANN }\end{array}$ \\
\hline \multirow{4}{*}{ Wave height } & $\operatorname{Bias}(\mathrm{m})$ & -0.06 & 0.16 & 0.00 \\
\hline & RMSE (m) & 0.29 & 0.35 & 0.09 \\
\hline & Scatter Index (\%) & 65.19 & 78.7 & 20.20 \\
\hline & $R^{2}$ & 0.42 & 0.45 & 0.94 \\
\hline \multirow{4}{*}{ Wave period } & Bias (s) & -0.98 & -0.59 & 0.00 \\
\hline & RMSE (s) & 1.13 & 0.80 & 0.22 \\
\hline & Scatter Index (\%) & 37.84 & 26.91 & 7.40 \\
\hline & $R^{2}$ & 0.42 & 0.47 & 0.91 \\
\hline
\end{tabular}


Table 2 The summary of statistical analysis of wave prediction in the analyzed scenarios for Kuwait station

\begin{tabular}{|c|c|c|c|c|}
\hline $\begin{array}{c}\text { Wave } \\
\text { characteristics }\end{array}$ & $\begin{array}{l}\text { Statistical } \\
\text { Parameter }\end{array}$ & $\begin{array}{c}\text { Modeled by } \\
\text { default parameter }\end{array}$ & $\begin{array}{c}\text { Modeled by } \\
\text { updated parameter }\end{array}$ & $\begin{array}{c}\text { modified } \\
\text { by } A N N\end{array}$ \\
\hline \multirow{4}{*}{ Wave height } & Bias (m) & 0.051 & 0.21 & 0.00 \\
\hline & RMSE (m) & 0.16 & 0.28 & 0.05 \\
\hline & Scatter Index (\%) & 54.42 & 94.73 & 17.09 \\
\hline & $R^{2}$ & 0.67 & 0.70 & 0.96 \\
\hline \multirow{4}{*}{ Wave period } & Bias (s) & -0.535 & -0.23 & 0.00 \\
\hline & RMSE (s) & 0.79 & 0.62 & 0.19 \\
\hline & Scatter Index (\%) & 33.04 & 26.0 & 8.11 \\
\hline & $R^{2}$ & 0.66 & 0.64 & 0.96 \\
\hline
\end{tabular}


Table 3 Comparison of the wave parameters estimated by ANN and error prediction approach.

This table also shows the evaluation of the effect of the modeled wave parameters on the accuracy of the error prediction. ANN1 are the networks with modeled wave parameters and ANN2 are the networks without modeled wave parameters

\begin{tabular}{ccccc}
\hline $\begin{array}{c}\text { Wave } \\
\text { characteristics }\end{array}$ & $\begin{array}{c}\text { Statistical } \\
\text { Parameter }\end{array}$ & $\begin{array}{c}\text { Direct prediction } \\
\text { by ANN }\end{array}$ & $\begin{array}{c}\text { Error prediction } \\
\text { by ANN1 }\end{array}$ & $\begin{array}{c}\text { Error prediction } \\
\text { by ANN2 }\end{array}$ \\
\cline { 2 - 5 } Wave height & Bias (m) & 0.00 & 0.00 & 0.00 \\
\cline { 2 - 5 } & RMSE (m) & 0.10 & 0.09 & 0.16 \\
\cline { 2 - 5 } & Scatter Index (\%) & 15.26 & 13.58 & 23.90 \\
\hline \multirow{3}{*}{ Wave period } & $R^{2}$ & 0.97 & 0.98 & 0.92 \\
\cline { 2 - 5 } & Bias (s) & 0.00 & 0.00 & -0.01 \\
\cline { 2 - 5 } & RMSE (s) & 0.30 & 0.21 & 0.31 \\
\cline { 2 - 5 } & Scatter Index (\%) & 8.91 & 6.34 & 9.21 \\
\cline { 2 - 5 } & $R^{2}$ & 0.90 & 0.95 & 0.89 \\
\hline
\end{tabular}

